\title{
Recurrent Grade 2 Follicular Lymphoma
}

National Cancer Institute

\section{Source}

National Cancer Institute. Recurrent Grade 2 Follicular Lymphoma. NCI Thesaurus. Code C8156.

The reemergence of grade 2 follicular lymphoma after a period of remission. 